\title{
Cephalometric evaluation of the pharyngeal airway space after orthognathic surgery and distraction osteogenesis of the jaw bones
}

\author{
S. Ganapathy Sriram, Neelam N. Andrade \\ Department of Oral and Maxillofacial Surgery, Nair Hospital Dental College, Mumbai Central, Mumbai, Maharashtra, India
}

Address for correspondence: Dr. Nelam N Andrade, Department of Oral and Maxillofacial Surgery, Nair Hospital Dental College, Mumbai Central, Mumbai - 400 008, Maharashtra, India. E-mail: drnnandrade@yahoo.co.in

\section{ABSTRACT}

Objective: Orthognathic surgeries and distraction osteogenesis (DO) of the jaw bones cause a change in the pharyngeal airway space (PAS). The aim of our study was to evaluate the magnitude of changes occurring in the pharyngeal airway after mandibular set-back surgeries and DO of maxilla/mandible. Materials and Methods: The study undertaken was a retrospective cephalometric study. Subjects included in our study had undergone mandibular set-back surgery or DO of maxilla/mandible. Lateral cephalograms of the subjects taken pre-operatively (T0), immediate post-operatively (T1) and after a minimum follow-up period of 6 months (T2) were studied. The cephalograms were traced manually and the following parameters were evaluated: Surface area of the PAS, pharyngeal airway width at the level of the base of the tongue, position of the hyoid bone and the tongue. Repeated measure ANOVA test was done to assess the presence of any significant changes in the proposed parameters at T0, T1 and T2. A correlation analysis was made between the mandibular/maxillary movements and the corresponding changes in the PAS. Results: Surgical movements of maxilla and mandible do have an effect on the pharyngeal airway. Conclusion: It was clearly evident that the effects of mandibular movements on the PAS and the hyoid bone is more significant than the maxillary movements.

\section{KEY WORDS}

Distraction osteogenesis; orthognathic surgery; pharyngeal airway space

\section{INTRODUCTION}

rthognathic surgeries and distraction osteogenesis (DO) have become routine procedures to correct various cranio-facial deformities. Successful

\begin{tabular}{|l|l|}
\hline \multicolumn{2}{|c|}{ Access this article online } \\
\hline Quick Response Code: & Website: \\
\hline & www.ijps.org \\
\cline { 2 - 2 } & Dol: \\
\hline
\end{tabular}

surgeries besides providing good cosmetic results, also give good masticatory efficiency and dento-facial harmony.

The soft tissue changes and their adaptations following orthognathic surgery and DO have been well-documented in the literature. Initially, the effect of these surgeries on the pharyngeal soft tissues and airway space were not realised and hence were not evaluated. The soft palate, tongue, hyoid bone and associated muscles are attached either directly or indirectly to the maxilla and the mandible. Hence, any movement involving the maxilla and mandible can also cause a corresponding change in 
the soft tissues attached to it. Wickwire et al. in 1972 reported the effect of mandibular osteotomy on the tongue posture and hyoid bone. ${ }^{[1]}$ Guilleminault et al. in 1985 reported sleep apnoea in normal subjects following mandibular osteotomy for retrusion. ${ }^{[2,3]}$ Riley et al. in 1987 reported two cases of obstructive sleep apnoea (OSA) following surgery for correction of mandibular prognathism. ${ }^{[4]}$ Lately, extensive research has been carried out to study the implications of cranio-facial skeleton movements on pharyngeal soft tissues. However, there are differing opinions about the extent and duration of post-operative changes on the posterior pharyngeal airway space (PAS), position of the hyoid bone and the tongue posture.

A significant increase in the PAS was observed following maxillary-mandibular advancements. ${ }^{[2,5,6]}$ Alternatively, mandibular setback surgeries are known to reduce the PAS. The airway space at the level of the posterior border of the tongue (PBT) is at a more risk than the airway space at the level of the soft palate. Obviously, then larger mandibular setback movements can increase the risk of developing OSA. Several studies attempted to evaluate the magnitude of an increase or decrease in PAS at the level of the base of the tongue. There are few studies evaluating the changes in the sagittal cross-sectional area of the PAS after mandibular osteotomies. Most of these studies investigated the effect of mandibular setback surgeries for mandibular prognathism. The effect of maxillary osteotomies on the PAS was assumed to have no significant clinical implications and have not been sufficiently explored.

Initial studies suggested on the reflex physiologic adaptation of the hyoid bone following mandibular osteotomy. ${ }^{[7,8]}$ Wickwire et al. reported about the downward and backward movement of the hyoid bone immediately after the surgery to correct class III malocclusion followed by its tendency to return towards its original position. ${ }^{[1]}$ Studies by Athanasiou et al. showed the hyoid bone movement was more in the downward direction following mandibular set-back osteotomies. ${ }^{[9]}$ Tselnik and Pogrel reported on the return of the hyoid bone to its original position following mandibular setback osteotomy after initial adaptation in the postoperative period. ${ }^{[10]}$ Long-term studies on the hyoid bone position following mandibular set back surgeries have shown that the hyoid bone never regains its original pre-operative position. ${ }^{[11,12]}$ The movement of hyoid bone after mandibular set-back surgeries is thought to be an adaptation to decrease the encroachment of the tongue on the PAS. Hence, displacement of the PBT after mandibular surgeries causes a corresponding movement of the hyoid bone. The movements of the hyoid bone and tongue after advancement surgery of the maxilla have no much clinical significance and have not been extensively researched.

The purpose of our study was to evaluate the effect of mandibular DO, mandibular DO with genioplasty, mandibular set-back and maxillary DO on the PAS, position of the tongue and hyoid bone both pre- and post-operatively and also to relate the extent of the surgical movement of the jaw bones that may correspondingly have a significant effect on the PAS. Lateral cephalograms being in-expensive and its facility available in most hospitals was considered and taken into the study.

\section{MATERIALS AND METHODS}

Data from 34 patients who underwent orthognathic surgery/DO for correction of their dento-facial deformity were included in the study. Of the 34 patients, 15 underwent mandibular DO, 4 underwent mandibular DO with genioplasty, 8 underwent bilateral sagittal split osteotomy for mandibular set back and 7 underwent maxillary DO. Mandibular DO with genioplasty was considered only for those patients with severe mandibular retrognathism. Pre (T0) and Immediate post-operative (T1) Polysomnography studies were performed in all the patients who underwent mandibular advancement surgeries to evaluate sleep apnoea. The mean preoperative age of the subjects was 18.6 years. Standard DO protocol was followed for patients who underwent DO, which included 4 days of latency period, followed by distraction of the maxilla/mandible to appropriate maxillomandibular relationship followed by a consolidation period of 4 months. Lateral cephalograms were taken pre-operatively (T0), immediate post-operatively (T1) and after 6 months post-operatively (T2). For subjects undergoing DO, immediate post-operative (T1) refers to the time period after the maxilla/mandible has been distracted to the desired length. All lateral cephalograms were taken using a standardised method which involves stabilizing the patient's head in natural position with the sagittal plane parallel to the film and Frankfurt horizontal plane parallel to the floor, teeth in occlusion with lips relaxed. Bilateral ear rods were gently inserted into the 
external auditory meatus, orbital pointer touching the orbitale and the nasion holder was gently placed over the bridge of the nose.

\section{Cephalometric analysis}

All lateral cephalograms were traced by hand onto an acetate paper. The cephalometric landmarks used in this study are shown in Figure 1. The cephalograms were evaluated for a change in the PAS surface area, PAS width, horizontal hyoid position, vertical hyoid position and antero-posterior tongue position. Frankfurt horizontal plane (FH plane) was taken as the standard horizontal reference plane. A line drawn perpendicular to $\mathrm{FH}$ plane through Sella $(\mathrm{S})$ was taken as the standard vertical reference plane.

\section{Calculation of surface area of pharyngeal airway space}

A line drawn parallel to Frankfurt Horizontal (FH) plane passing through posterior nasal spine formed the superior border. A line drawn across the superior aspect of epiglottis (SEG) parallel to FH defined the inferior border. The anterior border was defined as the

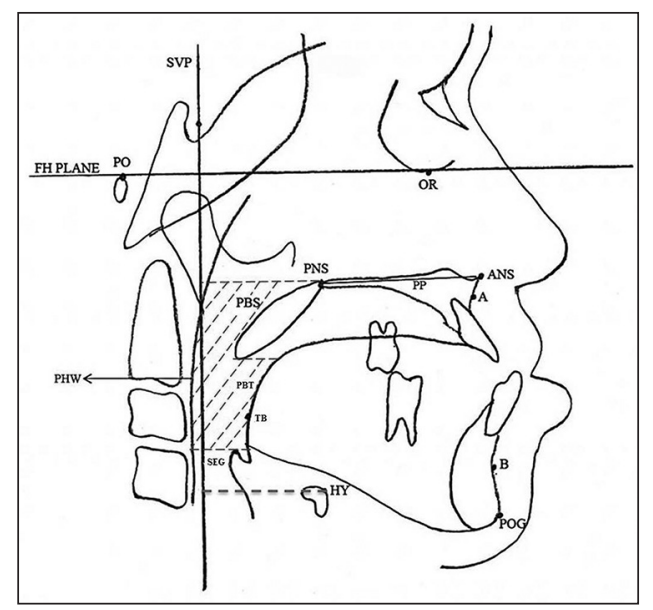

Figure 1: Cephalometric Landmarks-Orbitale (OR): The lowest point on the inferior margin of the orbit, midpoint of the left and right bony orbit images,

Porion (PO): The superior-most point of the external auditory meatus, Posterior nasal spine (PNS): The tip of the posterior nasal spine - the most posterior point at the sagittal plane on the bony hard palate, Superior aspect of epiglottis (SEG): The most superior point on the outline of the superior border of the epiglottis, Posterior border of tongue(PBT): The outline of the posterior border of the dorsum of the tongue, Posterior border of soft palate (PBS): The outline of the posterior border of the soft palate, Dorsum of tongue (TB): The most posterior point on the dorsum of the tongue closest to the posterior pharyngeal wall $(\mathrm{PHW}$ ) when oriented to the $\mathrm{FH}$ plane, $\mathrm{PHW}$ : The radiographic outline of the posterior wall of the pharynx, Pogonion (POG): The most anterior point on the bony chin in the median plane, Hyoid (HY): The most superior and anterior point on the body of the hyoid, Frankfort horizontal plane (FH plane): The line joining porion to orbitale, Sella (S): Geometric centre of the pituitary fossa located by visual inspection, Sella vertical plane (SVP): A vertical line perpendicular to the $\mathrm{FH}$ plane passing through the Sella (S), Anterior nasal spine (ANS): The anterior tip of the sharp bony process of the maxilla at the lower margin of the anterior nasal opening, Palatal plane (PP): The line joining the ANS and the PNS. PAS surface area: Area bounded by the dashed line posterior border of the soft palate (PBS) and tongue (PBT) extending up to the epiglottis (SEG). Posterior border was formed by posterior pharyngeal wall (PHW). The surface area of the PAS $\left(\mathrm{mm}^{2}\right)$ was calculated by superimposing the acetate matt paper over the $1 \mathrm{~mm}^{2}$ grid paper.

\section{Pharyngeal width}

The width of the pharyngeal airway in mm was calculated as the distance between the point on the posterior border of the dorsum of the tongue closest to the pharyngeal wall (TB) and the corresponding point on the PHW, parallel to the FH plane.

\section{Tongue position change}

The amount of anterior or posterior tongue displacement corresponded to the change in values of sella vertical plane (SVP) to TB, drawn parallel to FH.

\section{Hyoid bone position change}

The position of the hyoid bone was determined in the vertical and horizontal planes. The anterior-posterior (Horizontal) movement of the hyoid bone was calculated as the change in length between SVP to HY, drawn parallel to FH. The superior-inferior (Vertical) movement of the hyoid bone was calculated as the change in values between FH and the line parallel to FH through HY.

\section{Statistical analysis}

Each of the above-mentioned groups was tabulated and analysed separately for changes in the proposed parameters. Since the data were collected from the same subjects at three points of time namely, pre-operative (T0), post-operative (T1) and after follow-up of 6 months (T2), comparison was made between these three records with a repeated measure ANOVA test. If ANOVA test was significant then post-hoc test (Boneferoni test) was done to identify which of the means (T1-T0, T2-T0 and T2-T1) differed significantly. The changes in the proposed parameters were correlated to the extent of the surgical movements of the jaws [Table 1].

\section{Table 1: Correlation analysis of antero-posterior skeletal movements with the PAS surface area, PAS width and the} tongue position

\begin{tabular}{lccc}
\hline Procedure & $\begin{array}{c}\text { PAS surface } \\
\text { area }\end{array}$ & $\begin{array}{c}\text { PAS } \\
\text { width }\end{array}$ & $\begin{array}{c}\text { Tongue } \\
\text { position }\end{array}$ \\
\hline Mandibular DOG & 0.353 & 0.145 & 0.456 \\
Mandibular DOG with genioplasty & 0.94 & 0.95 & 0.94 \\
Mandibular set-back & 0.22 & 0.70 & 0.42 \\
Maxillary DOG & 0.73 & 0.17 & -0.39 \\
\hline
\end{tabular}

PAS: Pharyngeal airway space 


\section{RESULTS}

The mean age of the patients who underwent mandibular DO, mandibular DO with genioplasty, mandibular set-back and maxillary distraction were 17.13, 21, 20.5 and 16.14 years respectively. Positive values denote advancement movements and negative values denote set-back movements. Insignificant supero-inferior movement was evident with maxillary DO. The mean skeletal movement carried out in each group is shown in Table 2. Late postoperative results showed near nil skeletal changes in mandibular DO group. Genioplasty was performed at the end of the consolidation period in mandibular DO with genioplasty group. Hence in this group, the point PG advanced further by $2.5 \mathrm{~mm}$ at T2. Late post-operative results of maxillary DO showed nil skeletal changes at T2. In mandibular set-back group, a minimal relapse of $1.37 \mathrm{~mm}$ was observed in the late post-operative period (T2). Changes in Apnoea-Hypopnea index and oxygen saturation measured in polysomnography of the patients in Mandibular DO and Mandibular DO with Genioplasty group are shown in Tables 3 and 4, respectively.

The changes in the PAS surface area and PAS width through $\mathrm{T} 1$ and T2 are shown in Figures 2 and 3, respectively. The horizontal and vertical hyoid bone movements are shown in Figures 4 and 5, respectively. Antero-posterior changes in the position of the tongue corresponding to the skeletal movements are shown in Figure 6.

\section{DISCUSSION}

Our cephalometric study evaluating changes in PAS, tongue position and hyoid bone position showed variable results corresponding to the skeletal movements performed to correct the facial deformity. The cases selected in this study were those who had undergone

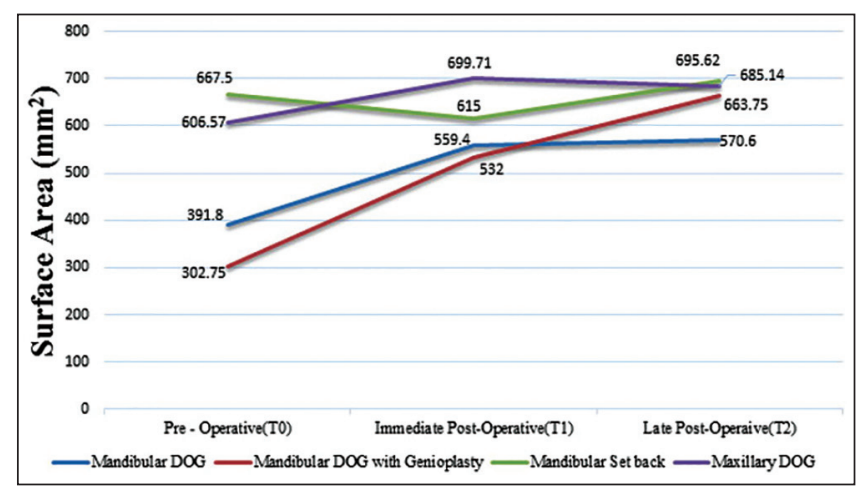

Figure 2: Changes in the pharyngeal airway space surface area
DO and orthognathic surgeries to correct their facial deformity. Subjects were grouped based on the procedure performed. 34 patients were considered for the study with a mean age of 18.6 years. Among the selected

Table 2: Changes in the mandible/maxilla position relative to vertical reference plane

\begin{tabular}{lcc}
\hline Procedure & T0-T1 $(\mathbf{m m})$ & T2-T1 $(\mathbf{m m})$ \\
\hline Mandibular DOG & +9.9 & -0.73 \\
Mandibular DOG with genioplasty & +10.25 & +2.5 \\
Mandibular set-back & -6.12 & +1.37 \\
Maxillary DOG & +8.75 & -0.57 \\
\hline
\end{tabular}

Table 3: Changes in polysomnography in mandibular DO group

\begin{tabular}{lcccc}
\multicolumn{2}{c}{ Apnoea-hypopnoea index } & & \multicolumn{2}{c}{ Mean oxygen saturation (\%) } \\
\cline { 1 - 2 } \cline { 5 - 5 } Pre & Post & & Pre & Post \\
\hline 10 & 1.7 & & 93.7 & 98.4 \\
13 & 0.9 & & 92.5 & 96.5 \\
7 & 1.4 & & 92.6 & 97.3 \\
9 & 1.9 & & 89.4 & 96.4 \\
20 & 1.2 & & 93.4 & 98.6 \\
25 & 0.8 & & 92.3 & 97.4 \\
28 & 1.4 & & 94 & 96.9 \\
22 & 1.2 & & 90.8 & 95.8 \\
47 & 1.8 & & 88.4 & 96.8 \\
46.5 & 1.7 & & 89.6 & 96.4 \\
46 & 0.6 & & 91.3 & 95.9 \\
46.4 & 2.2 & & 88.3 & 95.8 \\
46.4 & 1.4 & & 92.1 & 98.3 \\
46.9 & 1.6 & & 90.3 & 97.2 \\
46.5 & 1.8 & & 89.8 & 96.3 \\
\hline
\end{tabular}

DO: Distraction osteogenesis

Table 4: Changes in polysomnography in mandibular DO with genioplasty group

\begin{tabular}{|c|c|c|c|}
\hline \multicolumn{2}{|c|}{ Apnoea-hypopnoea index } & \multicolumn{2}{|c|}{ Mean oxygen saturation (\%) } \\
\hline Pre & Post & Pre & Post \\
\hline$\overline{42.3}$ & 1.7 & 93.7 & 98.4 \\
\hline 47 & 0.9 & 92.5 & 96.5 \\
\hline 46.3 & 1.4 & 92.6 & 97.3 \\
\hline 46.4 & 1.9 & 89.4 & 96.4 \\
\hline
\end{tabular}

DO: Distraction osteogenesis

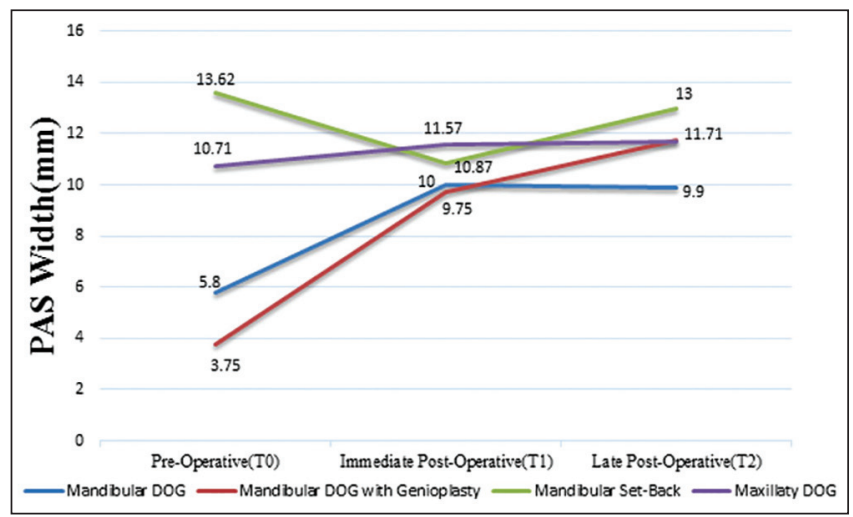

Figure 3: Changes in the pharyngeal airway space width 


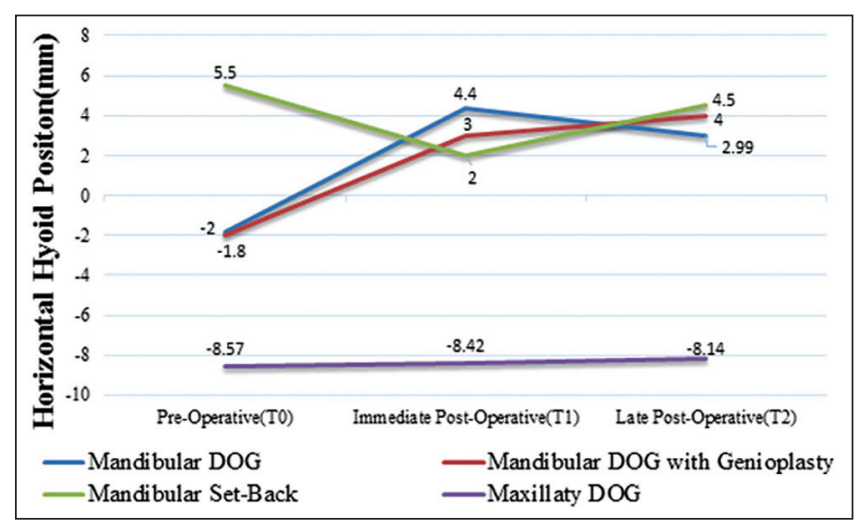

Figure 4: Changes in the horizontal position of the hyoid bone

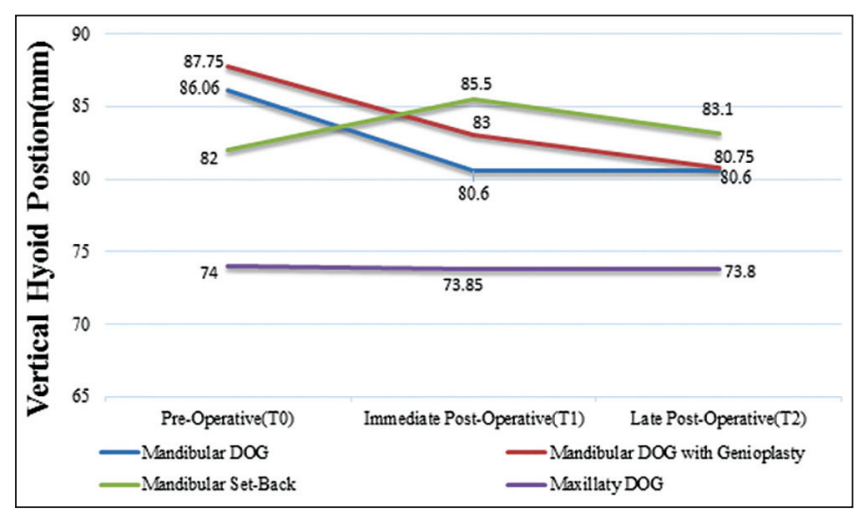

Figure 5: Changes in the vertical position of the hyoid bone

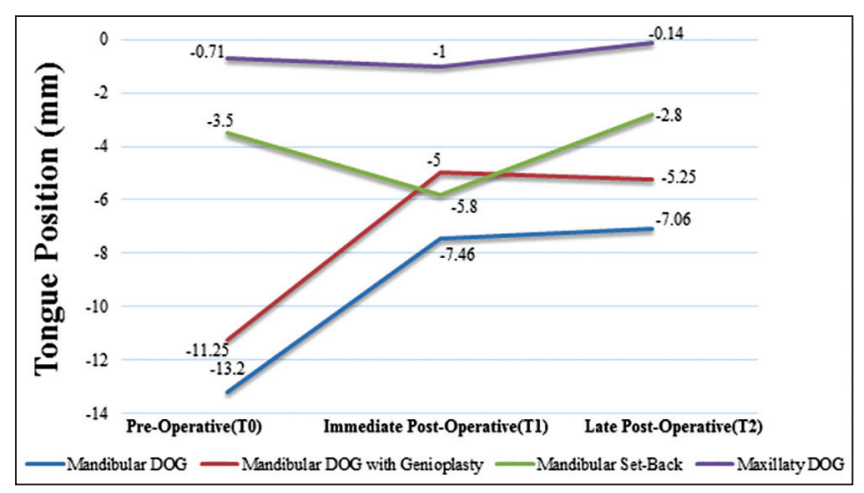

Figure 6: Changes in the position of the tongue

patients, maximum patients were in the age group of $<20$ years. Each of the proposed parameters were examined for changes in their position following mandibular DO, mandibular DO with genioplasty, mandibular set-back and maxillary DO.

\section{Pharyngeal airway space}

An increase in the PAS surface area was evident with advancement surgeries of the mandible. In our study, the PAS surface area increased by $42 \%\left(167.6 \mathrm{~mm}^{2}\right)$ following mandibular DO and by $56 \%\left(229.25 \mathrm{~mm}^{2}\right)$ following mandibular DO with genioplasty in the early post-operative period. The base of the tongue in close proximity to the pharyngeal wall was considered in this study for evaluating the PAS width. The mean PAS width increased by $4.2 \mathrm{~mm}$ following mandibular DO and by $6 \mathrm{~mm}$ following mandibular DO with genioplasty in the early post-operative period. No significant decrease in the PAS surface area or PAS width was evident after longterm follow-up in the mandibular DO group. However, there was a mean increase of $2 \mathrm{~mm}$ in PAS width in mandibular DO with genioplasty group after a 6 months follow-up. This was in concordance to the increase in the mean PAS surface area in the follow-up period by 131 $\mathrm{mm}^{2}$ from the early post-operative period. Correlation analysis showed strong positive correlation of mandibular movement with PAS surface area in both mandibular DO and mandibular DO with genioplasty group. Significant positive correlation was found between the PAS width and the mandibular movements in the above mentioned groups [Table 1]. The results proved that mandibular distraction with genioplasty was a superior technique that increased the width of the PAS. According to Hernández-Alfaro et al., mandibular advancement surgeries increased airway space by $78 \% .^{[13]}$ Turnbull and Battagel found that with the advancement of the mandible, the retropalatal and retrolingual dimensions of the airway increase significantly. ${ }^{[14]}$ The impact of mandibular advancement on the PAS was consistent with the results of other studies performed. ${ }^{[15,16]}$ Longterm follow-up showed no significant decrease either in the PAS surface area nor in the PAS width. In both the above-mentioned groups, the patients were relieved of the symptoms of apnoea post-operatively. ${ }^{[17]}$ This was also evident in post-operative poly-somnography studies. There was considerable reduction in apnoea/ hypopnoea events with marked improvement in oxygen saturation [Tables 3 and 4]. The average decrease in surface area observed in the early post-operative period in the mandibular set-back group was $7 \%\left(52 \mathrm{~mm}^{2}\right)$. Correspondingly, the PAS width decreased by $2.7 \mathrm{~mm}$ in the early post-operative period. Follow-up observations after 6 months showed an average relapse of $1.3 \mathrm{~mm}$. However, the PAS surface area showed an increase by $13 \%$ $\left(80 \mathrm{~mm}^{2}\right)$ and PAS width too showed an increase by an average of $2.12 \mathrm{~mm}$ at T2. One have reported an initial increase in the PAS after the mandibular setback surgery followed by a gradual decrease after a minimum follow-up of 6 weeks. ${ }^{[10]}$ According to a study by Eggensperger et al., the nasopharyngeal, oropharyngeal and hypopharyngeal airway spaces remained decreased at the end of the $1^{\text {st }}$ year after mandibular set-back surgery. ${ }^{[11]}$ He also 
reported that the diameter of the lower pharyngeal airway remained almost unchanged. In this study, the immediate decrease in the PAS in the early post-operative period in mandibular set-back group is probably due to a sudden encroachment of the tongue into the PAS. During the early post-operative period, there is often soft tissue inflammation and swelling secondary to surgery. The inflamed soft tissues encroach on the pharyngeal airway, thereby potentially compromising its patency. ${ }^{[10]}$ Longterm follow-up showed increase in the PAS surface area to near pre-operative levels in most of the cases. The mean PAS surface area after long-term follow-up was in fact greater than the mean pre-operative values, which can be further attributed to a patient's normal growth in the growing patients. Reports also suggest that there is a gradual adaptation of the hyoid bone and pharyngeal soft tissue to maintain the patency of the airway. ${ }^{[0]}$

The average maxillary advancement carried out in this study through DO was $8.75 \mathrm{~mm}$. Very minimal superoinferior movement of the maxilla was evident. Long-term follow-up showed stable results. The PAS surface area increased by $15 \%\left(93.14 \mathrm{~mm}^{2}\right)$. However, the PAS width in the retro-lingual region showed a mean increase of 1 $\mathrm{mm}$, which is not so significant. The increase in the PAS surface area is due to the retro-palatal increase in airway space due to the advancement of the maxilla. Long-term follow-up showed an insignificant decrease in the PAS surface area and PAS width. According to Greco et al., with advancement of maxilla, the tongue moves forward to assume a more normal position and thereby increases the hypopharyngeal airway space. ${ }^{[18]}$

Our study showed that with the advancement of the maxilla, there was a corresponding increase in the PAS surface area but this had no impact on the retro-lingual PAS width.

\section{Hyoid position}

With mandibular advancement, the hyoid bone occupied a significant anterior and superior position, which was in concordance to other studies. ${ }^{[19-21]}$ La Banch and Epker reported short-term anterior movement of the hyoid bone after mandibular advancement. However, after follow-up period, the hyoid bone was observed to be in a significantly anterior position as compared to its presurgical position. ${ }^{[21]}$ In our study, the mean anterior and superior movement of the hyoid bone in mandibular DO group was by $6.4 \mathrm{~mm}$ and $5.5 \mathrm{~mm}$, respectively. In the mandibular DO with genioplasty group, the hyoid bone moved anteriorly and superiorly by an average of $4.8 \mathrm{~mm}$ and $4.7 \mathrm{~mm}$, respectively. At T2, in mandibular DOG group, the hyoid bone moved posteriorly by $1.4 \mathrm{~mm}$, vertical position remained unchanged. In mandibular DOG with genioplasty group, the hyoid bone at T2 moved posteriorly and inferiorly by 1 and $2.25 \mathrm{~mm}$, respectively. Long-term follow-up showed the position of hyoid bone to be significantly anterior and superior to its presurgical position in the above-mentioned groups. Some researchers claim that the hyoid bone re-adapts to its presurgical position in long-term follow-up periods. ${ }^{[21]}$

With mandibular set-back, the mean posterior and inferior movement of the hyoid bone was by $3.5 \mathrm{~mm}$ in the immediate post-operative period. In accordance to other studies, an initially posterior and inferior movement of the hyoid bone was observed. ${ }^{[22-24]}$ Reports suggest that this movement is a physiologic adaptation to prevent hyoid bone-related encroachment on the pharyngeal airway in the immediate post-operative period. ${ }^{[10]}$ At long-term follow-up, the hyoid bone moved anteriorly and superiorly by an average of $2.5 \mathrm{~mm}$ and $2.4 \mathrm{~mm}$, respectively from its immediate post-surgical position. The results in this study showed a tendency of the hyoid bone to attain its pre-surgical position. Several other studies showed the post-operative displacement of the hyoid bone was maintained 1 year post-operatively, ${ }^{[10,22,25]}$ whereas others observed a tendency of the hyoid bone to return to its pre-operative postion..$^{[9,26]}$ In our study, the movement of the hyoid bone was in concordance to other studies in the early post-operative period, and a follow-up of $>6$ months showed its movement to a near pre-surgical position.

With maxillary advancements, the hyoid bone showed insignificant movements in the early and late post-operative periods after maxillary DO. The maxillary advancement surgeries seem to have no effect on the position of the hyoid bone. According to Lee et al., there was neither an anteroposterior nor a vertical positional change in the hyoid bone following maxillary protraction. He reported an increase in length without thickness change in the tongue and soft palate following maxillary advancements. ${ }^{[27]}$ No significant changes in the position of the hyoid bone have been reported following maxillary surgeries.

\section{Tongue position}

With mandibular advancement surgeries, the tongue moved anteriorly in concordance to the skeletal advancement. In our study, the mean anterior displacement of the tongue 
at T1 with mandibular DO and mandibular DO with genioplasty was by 5.8 and $6.25 \mathrm{~mm}$ respectively. A greater anterior tongue movement was evident with mandibular DO with genioplasty, corresponding to larger mandibular advancement achieved. Long-term post-operative findings showed no significant change in the position of the tongue. In both the groups, the tongue movement showed strong positive correlation with the PAS width and the hyoid bone positions. Since the PHW remained static, any mandibular skeletal movements carried out had a direct effect on the position of the tongue and consequently on the PAS. The retroglossal PAS width seems to have a direct relationship with the position of the tongue. A study by Yu et al. reported a mean ratio relating an increase in PAS width at the base of the tongue and the mandibular advancement to be $0.19: 1{ }^{[28]}$

With mandibular set-back surgery, the tongue moved posteriorly encroaching upon the PAS. The mean posterior tongue movement following mandibular set back surgeries in this study was $2.37 \mathrm{~mm}$. The mean mandibular set back carried out was $6.12 \mathrm{~mm}$. Correlation analysis showed a positive correlation of the tongue movement with PAS width [Table 1]. However, interestingly none of the patients developed respiratory distress following surgery. The base of the tongue is considered to be at the highest risk in mediating apnoea following mandibular set-back surgeries due to its close proximity to the PHW. In T2, the tongue moved anteriorly to its near pre-surgical position. Partinen et al. noted in 157 OSA patients that those with a PAS width of $<5 \mathrm{~mm}$ had the highest respiratory distress index. ${ }^{[29]}$ It was also postulated that the initial inflammatory process increased the thickness of the soft tissues and narrowed the airway. Berger et al. indicated that the pathologic changes such as vascular engorgement, fibrosis, edema and inflammatory cell infiltration are probably the sequelae of airway obstruction rather than its cause. ${ }^{[30]}$ Considering the risk of developing obstructive sleep apnoea, Chen et al. postulated an equation to predict the change in the PAS after mandibular set-back surgery. ${ }^{[31]}$

With maxillary advancement, our study showed no effect on tongue position. Hiyama et al. reported that the positional change in the tongue causes a forward positioning of the soft palate, leading to an increased upper airway width. ${ }^{[32]}$ As the maxilla is advanced, the soft palate moves forward, the angle between the hard and soft palate becomes more obtuse, and the soft palate lengthens. ${ }^{[33]}$ According to Profitt and White, the tongue adapts to maxillary surgery. They reported that when the maxilla is advanced or retracted, the tongue moves forward to assume a more normal position. ${ }^{[34]}$ Greco et al. have reported an increase in the hypopharyngeal airway space after advancement of the maxilla. ${ }^{[18]}$ According to them, when the maxilla is advanced or impacted, the tongue moves forward to assume a more normal position and thereby increases the hypopharyngeal airway space. In this study, an increase in the PAS was observed after maxillary advancement; however, the position of the tongue remained unaffected. The increase in airway space is probably due to a retro-palatal increase in the pharyngeal airway surface area.

This study showed an increase in the PAS surface area with advancement surgeries of the mandible and maxilla. The PAS width at the PBT had significant positive correlation with the skeletal movement of the mandible. Maximum increase in the PAS width was observed after mandibular advancement with genioplasty. The hyoid bone too showed positive correlation with the skeletal movement of the mandible. Maxillary advancement surgery showed no significant changes in the position of the hyoid bone. The accurate post-operative change in the surface area and width of the PAS, hyoid bone position and tongue position appeared to be variable and difficult to predict pre-operatively with the quantum of skeletal movements planned for the patient.

\section{REFERENCES}

1. Wickwire NA, White RP Jr, Proffit WR. The effect of mandibular osteotomy on tongue position. J Oral Surg 1972;30:184-90.

2. Guilleminault C, Riley R, Powell N. Obstructive sleep apnea and abnormal cephalometric measurements. Implications for treatment. Chest 1984;86:793-4.

3. Guilleminault C, Riley R, Powell N. Sleep apnea in normal subjects following mandibular osteotomy with retrusion. Chest 1985;88:776-8.

4. Riley RW, Powell NB, Guilleminault C, Ware W. Obstructive sleep apnea syndrome following surgery for mandibular prognathism. J Oral Maxillofac Surg 1987;45:450-2.

5. Riley RW, Powell NB, Guilleminault C. Maxillary, mandibular, and hyoid advancement for treatment of obstructive sleep apnea: A review of 40 patients. J Oral Maxillofac Surg 1990;48:20-6.

6. Riley RW, Powell NB, Guilleminault C. Obstructive sleep apnea syndrome: A surgical protocol for dynamic upper airway reconstruction. J Oral Maxillofac Surg 1993;51:742-7.

7. Graber LW. Hyoid changes following orthopedic treatment of mandibular prognathism. Angle Orthod 1978;48:33-8.

8. Takagi Y, Gamble JW, Proffit WR, Christiansen RL. Postural change of the hyoid bone following osteotomy of the mandible. Oral Surg Oral Med Oral Pathol 1967;23:688-92.

9. Athanasiou AE, Toutountzakis N, Mavreas D, Ritzau M, WenzelA. Alterations of hyoid bone position and pharyngeal depth and their 
relationship after surgical correction of mandibular prognathism. Am J Orthod Dentofacial Orthop 1991;100:259-65.

10. Tselnik M, Pogrel MA. Assessment of the pharyngeal airway space after mandibular setback surgery. J Oral Maxillofac Surg 2000;58:282-5.

11. Eggensperger N, Smolka W, lizuka T. Long-term changes of hyoid bone position and pharyngeal airway size following mandibular setback by sagittal split ramus osteotomy. J Craniomaxillofac Surg 2005;33:111-7.

12. Kawakami M, Yamamoto K, Fujimoto M, Ohgi K, Inoue M, Kirita T. Changes in tongue and hyoid positions, and posterior airway space following mandibular setback surgery. J Craniomaxillofac Surg 2005;33:107-10.

13. Hernández-Alfaro F, Guijarro-Martínez R, Mareque-Bueno J. Effect of mono-and bimaxillary advancement on pharyngeal airway volume: Cone-beam computed tomography evaluation. J Oral Maxillofac Surg 2011;69:e395-400.

14. Turnbull NR, Battagel JM. The effects of orthognathic surgery on pharyngeal airway dimensions and quality of sleep. J Orthod 2000;27:235-47.

15. Yu LF, Pogrel MA, Ajayi M. Pharyngeal airway changes associated with mandibular advancement. J Oral Maxillofac Surg 1994;52:40-3.

16. Farole A, Mundenar MJ, Braitman LE. Posterior airway changes associated with mandibular advancement surgery: Implications for patients with obstructive sleep apnea. Int J Adult Orthodon Orthognath Surg 1990;5:255-8.

17. Andrade NN, Kalra R, Shetye SP. New protocol to prevent TMJ reankylosis and potentially life threatening complications in triad patients. Int J Oral Maxillofac Surg 2012;41:1495-500.

18. Greco JM, Frohberg U, Van Sickels JE. Cephalometric analysis of long-term airway space changes with maxillary osteotomies. Oral Surg Oral Med Oral Pathol 1990;70:552-4.

19. Valk JW, Zonnenberg AJ, van Maanen CJ, van Wonderen OG. The biomechanical effects of a sagittal split ramus osteotomy on the relationship of the mandible, the hyoid bone, and the cervical spine. Am J Orthod Dentofacial Orthop 1992;102:99-108.

20. Schendel SA, Epker BN. Results after mandibular advancement surgery: An analysis of 87 cases. J Oral Surg 1980;38:265-82.

21. LaBanc JP, Epker BN. Changes of the hyoid bone and tongue following advancement of the mandible. Oral Surg Oral Med Oral Pathol 1984;57:351-6.

22. Enacar A, Aksoy AU, Sençift $Y$, Haydar B, Aras K. Changes in hypopharyngeal airway space and in tongue and hyoid bone positions following the surgical correction of mandibular prognathism. Int J Adult Orthodon Orthognath Surg 1994;9:285-90.

23. Kawamata A, Fujishita M, Ariji Y, Ariji E. Three-dimensional computed tomographic evaluation of morphologic airway changes after mandibular setback osteotomy for prognathism. Oral Surg Oral Med Oral Pathol Oral Radiol Endod 2000;89:278-87.

24. Gu G, Gu G, Nagata J, Suto M, Anraku Y, Nakamura K, et al. Hyoid position, pharyngeal airway and head posture in relation to relapse after the mandibular setback in skeletal Class III. Clin Orthod Res 2000;3:67-77.

25. Achilleos S, Krogstad O, Lyberg T. Surgical mandibular setback and changes in uvuloglossopharyngeal morphology and head posture: A short- and long-term cephalometric study in males. Eur J Orthod 2000;22:383-94.

26. Samman N, Tang SS, Xia J. Cephalometric study of the upper airway in surgically corrected class III skeletal deformity. Int J Adult Orthodon Orthognath Surg 2002;17:180-90.

27. Lee JW, Park KH, Kim SH, Park YG, Kim SJ. Correlation between skeletal changes by maxillary protraction and upper airway dimensions. Angle Orthod 2011;81:426-32.

28. Yu L, Pogrel M, Ajayi M. Pharyngeal airway changes associated with mandibular advancement. J Oral Maxillofac Surgery 1994;52:40-43.

29. Partinen M, Guilleminault C, Quera-Salva MA, Jamieson A. Obstructive sleep apnea and cephalometric roentgenograms. The role of anatomic upper airway abnormalities in the definition of abnormal breathing during sleep. Chest 1988;93:1199-205.

30. Berger G, Gilbey P, Hammel I, Ophir D. Histopathology of the uvula and the soft palate in patients with mild, moderate, and severe obstructive sleep apnea. Laryngoscope 2002;112:357-63.

31. Chen F, Terada K, Hanada K, Saito I. Predicting the pharyngeal airway space after mandibular setback surgery. J Oral Maxillofac Surg 2005;63:1509-14.

32. Hiyama S, Suda N, Ishii-Suzuki M, Tsuiki S, Ogawa M, Suzuki S, et al. Effects of maxillary protraction on craniofacial structures and upper-airway dimension. Angle Orthod 2002;72:43-7.

33. Schendel SA, Oeschlaeger M, Wolford LM, Epker BN. Velopharyngeal anatomy and maxillary advancement. J Maxillofac Surg 1979;7:116-24.

34. Proffit WR, White RP. Combined orthodontic and surgical management of maxillary protrusion in adults. Am $\mathrm{J}$ Orthod 1973;64:368-83.

How to cite this article: Sriram SG, Andrade NN. Cephalometric evaluation of the pharyngeal airway space after orthognathic surgery and distraction osteogenesis of the jaw bones. Indian J Plast Surg 2014;47:346-53.

Source of Support: Nil, Conflict of Interest: None declared.

INDOCLEFTCON 2015
14th Annual Conference of Indian Society of Cleft Lip, Palate and
Craniofacial Anomalies
Venue: Holiday Inn Resort, Cavelossim, Goa.
Dates: 30th April to 3rd May 2015
Conference Secretariat: Dr. Shailesh Ranade, 203, Saiprasad, Jayprakash
Nagar, Road No. 3, Near Swati Studio, Goregaon East, Mumbai 400063.
Telephone: +919821166958
Email: indocleftcon2015@.amailicom.
Website: wwwindocleftcon2015.com.

